\title{
Mangrove-sponge associations: a possible role for tannins
}

\author{
Ellard R. Hunting • Harm G. van der Geest • \\ Annamarie J. Krieg • Marianne B. L. van Mierlo • \\ Rob W. M. van Soest
}

Received: 24 April 2009/Accepted: 10 December 2009/Published online: 30 December 2009

(C) The Author(s) 2009. This article is published with open access at Springerlink.com

\begin{abstract}
A positive correlation between sponge coverage and tannin concentrations in prop roots of Rhizophora mangle L. has previously been reported. However, the ecological role of tannins within the mangrove sponge association remains speculative. This study investigated whether tannins play a role in sponge recruitment and assessed tannin and polyphenol production in $R$. mangle roots in response to sponge colonization. We demonstrated in a field experiment using artificial substrates with different tannin concentrations that tannins are positively involved in larval recruitment of the sponge Tedania ignis and that roots significantly enhanced tannin and polyphenolic content in response to natural and experimental sponge fouling. Differential recruitment in response to tannins may have been the result of a
\end{abstract}

E. R. Hunting $(\varangle) \cdot$ H. G. van der Geest ·

A. J. Krieg - M. B. L. van Mierlo

Institute for Biodiversity and Ecosystem Dynamics,

Department of Aquatic Ecology and Ecotoxicology

(IBED-AEE), Universiteit van Amsterdam (UvA),

P.O. Box 94240, 1090 GE Amsterdam, The Netherlands

e-mail: e.r.hunting@uva.nl

R. W. M. van Soest

Zoological Museum, University of Amsterdam,

PO Box 94766, 1090 GT Amsterdam, The Netherlands behavioral response in sponge larvae. It is also possible that tannins affected the structure of the fouling microbial biofilm on the artificial substrate, or tannins affected the post-settlement dynamics of sponge recruits. Elevations in concentrations of tannins and polyphenolic compounds upon coverage with sponges, combined with differential recruitment of $T$. ignis in response to differences in tannin concentrations, may indicate a positive feedback in recruitment. This may in part explain the typical heterogeneity in sponge coverage and community composition among roots.

Keywords Substrate selection - Sponges · Tannins $\cdot$ Polyphenols $\cdot$ Mangroves · Recruitment

\section{Introduction}

Sponge communities in mangrove systems consist of species typical to this habitat but are spatially heterogeneous, i.e., neighboring roots can vary greatly in their sponge coverage and composition. This variability can partly be attributed to low recruitment rates, limited larval availability and interactions among sponges (Sutherland 1980; Bingham 1992; Engel and Pawlik 2005), or may be the result of chemically induced interactions between sponges and mangroves. 
Tannins and polyphenolic compounds constitute the greater portion of carbon leachates from mangrove leaves (Maie and Jaffe 2006), and concentrations of tannins and polyphenols may vary depending on tissue, growth stage, and environmental conditions (Northup et al. 1998; Lin et al. 2006). A positive correlation between sponge coverage and tannin concentrations in the roots of Rhizophora mangle L. was previously reported, in which roots with considerable sponge cover $(>40 \%)$ contained elevated tannin concentrations compared to unfouled roots (Hunting et al. 2008). This suggests that tannins and polyphenolic compounds in general are potentially involved in the mangrove sponge association.

The mechanism responsible for the observed relation remains speculative since the ecological functioning of tannins is ambiguous. Firstly, it has been speculated that tannins act as a settling cue for sponge larvae (Hunting et al. 2008) or provide a carbon source for epibiontic sponges (Ellison et al. 1996) as leached DOC precipitates are also a source of particulate food for metazoans (Baylor and Sutcliffe 1963; Kuznetsova et al. 1984). Secondly, increases in tannin concentrations may be a physiological response of mangrove roots to sponge fouling. A substantial number of studies have suggested that grazing and fouling are strongly correlated to increases in polyphenol concentrations in which polyphenols may form recalcitrant complexes that are resistant to biodegradation, thereby reducing palatability and inhibiting growth of fouling organisms (e.g., Schmitt et al. 1998). Thirdly, sponge presence may positively or negatively affect nutrient availability for $R$. mangle roots, thereby causing differences in secondary metabolite production. It has been hypothesized that excess carbon may be allocated to carbon-rich secondary metabolites in the absence of nutrients (Bryant et al. 1987), while several studies have provided evidence that nutrient enrichment enhances production of total phenolics and tannins in R. mangle (Feller 1995; Feller et al. 2003a, b).

The objective of this study was to evaluate whether tannins play a role in sponge recruitment and whether roots of $R$. mangle enhance production of tannins and total phenolics in response to sponge colonization. These aspects were addressed by performing in situ recruitment and translocation experiments.

\section{Materials and methods}

Study site

This study was conducted within Spaanse Water $\left(12^{\circ} 04^{\prime} 21.78^{\prime \prime} \mathrm{N}, 68^{\circ} 51^{\prime} 38.87^{\prime \prime} \mathrm{W}\right)$, an inner bay of Curaçao, N.A., Southern Caribbean sea (Fig. 1), in the period of March until June 2008. Detailed information on physicochemical characteristics is provided elsewhere (Hunting et al. 2008: and references therein). In brief, the site is moderately eutrophic with low turbidity. Distance to the nearest reef is $2.2 \mathrm{~km}$. Salinity is around $35 \mathrm{psu}$ and $\mathrm{pH}$ is around 8 . Tidal ranges are approximately $10 \mathrm{~cm}$, and resident sponge communities do not emerge during low tide. Sponge coverage is on average little over 10 percent of the total root substrate.

\section{Recruitment experiment}

The role of tannins in recruitment of sponge larvae was assessed with artificial substrates made from polymeric gels. This method proved useful in studies focusing on the retention of larval settlement (e.g., Henrikson and Pawlik 1995; Browne and Zimmer 2001). Tannins embedded in a matrix of agar diffuse into the overlying water. A total of 30 mimicry gels (surface area $88 \mathrm{~cm}^{2}$, volume $440 \mathrm{~cm}^{3} ; 20 \mathrm{~g} \mathrm{~L}^{-1}$ agar and $60 \mu \mathrm{M}$ ascorbic acid) consisted of three different treatments containing either $0,0.3$ or $1.8 \mathrm{nM}$ tannic acid (purity $>96 \%$, Sigma-Aldrich). Although the majority of phenolic compounds in

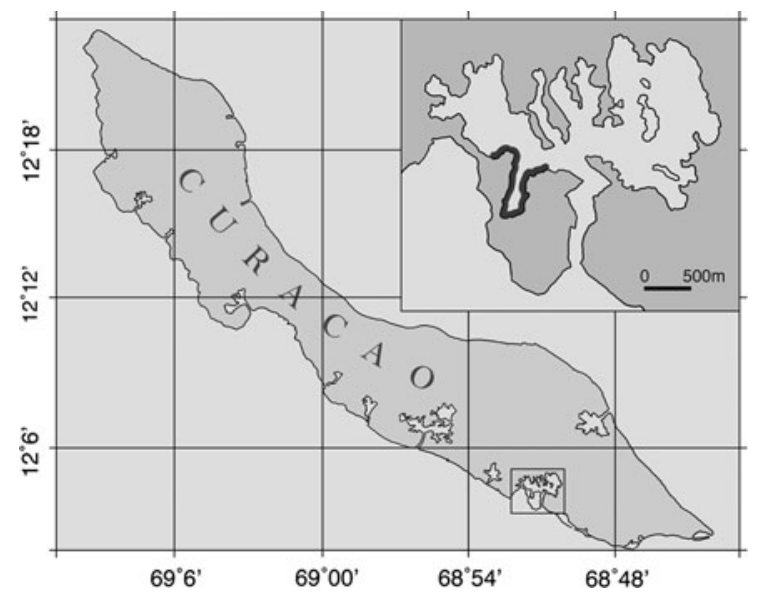

Fig. 1 Map of Curaçao and Spaanse Water (inset) showing location of the study site (shaded area) 
woody plants are condensed tannins, we used tannic acid as a representative of hydrolyzable tannins, the second major group of phenolics that occur primarily in young, rapidly growing tissues (e.g., prop roots of R. mangle) of woody plants (Haukioja et al. 1998). The mimicry gels were vertically installed with plastic rope throughout the mangrove fringes at approximately $0.8 \mathrm{~m}$ depth in a random fashion in order to minimize the effect of variable physicochemical conditions (e.g., flow conditions). Gels were placed within cages (mesh-size $1 \mathrm{~cm}^{2}$ ) to prevent spongivory. The average leaching rates of tannic acid from agar gels were approximated from a 7-week incubation in aquaria containing artificial seawater with starting concentrations of 0.3 and $1.8 \mathrm{nM}$. Leaching rates decreased about $40 \%$ over the course of the experiment but were still detectable after 7 weeks. The average leaching was $4( \pm 0.26 \mathrm{SD}) \mathrm{mgC} \mathrm{day}^{-1}$ and 15 ( $\pm 0.54 \mathrm{SD}) \mathrm{mgC}$ day $^{-1}$, respectively. The average leaching rates are comparable to leaching rates of total phenols (on average $2.4 \mathrm{mgC} \mathrm{day}^{-1}$ ) reported by Maie and Jaffe (2006), and dissolved organic carbon (on average $10 \mathrm{mgC} \mathrm{day}^{-1}$ ) reported by Camilleri and Ribi (1986). Conversion of reported leaching rates followed an empirical relation between root dry mass and root length reported by Ellison and Farnsworth (1996). Mimicry gels were collected after 7 weeks and brought to the laboratory. Gels remained submerged in seawater during transport to prevent exposure to air. Recovered recruits were prepared for microscopy in Canada balm. Species identification was based on microscopic examination of skeleton structure and spicule morphology following the nomenclature of Hooper and Van Soest (2002).

\section{Transplantation experiment}

A transplantation experiment with specimens of Tedania ignis was performed in order to determine whether sponge fouling can induce enhanced tannin and polyphenol production. Fifteen roots were selected for each of the following treatments: (1) natural root cover, in which sponge coverage exceeded $40 \%$ (primarily T. ignis); (2) bare roots that were not covered by any fouling organism during sampling; (3) bare roots used for transplantation of specimens of $T$. ignis (collected from neighboring roots and adjacent benthic substrata) attached with plastic cable ties as described by Ellison et al. (1996), in which we aimed to obtain a coverage that was comparable to treatment $2(>40 \%)$; and (4) bare roots that were wrapped in plankton net (mesh-size $500 \mu \mathrm{m}$ ), to allow natural turbidity to occur while preventing larval recruitment and isopod invasion, thereby ensuring that roots remained unfouled over the course of the experiment. The latter treatment served as an extra control for treatment 2 , for which there was no guaranteed absence of fouling organisms during the experiment. Mortality of transplants was $<5 \%$. Any losses within the first 2 weeks of the experiment were replaced. Samples (15-cm root segments) were collected after 8 weeks, wrapped in aluminum foil and immediately stored on ice. All samples were stored at $-20^{\circ} \mathrm{C}$ within $1 \mathrm{~h}$ after collection and remained frozen until analysis.

Analytical techniques

Root samples $(15-\mathrm{cm})$ were freeze-dried and ground with an electric coffee grinder (particle sizes ranged 200-300 $\mu \mathrm{m}$ ). Tannins and polyphenolic compounds were extracted from $100 \mathrm{mg}$ of ground sample as described previously (Hunting et al. 2008). Analysis of the protein-precipitating fraction of tannins is described in detail elsewhere (Hagerman 1987; Hunting et al. 2008). Total phenolics were determined using Folin-Ciocalteu reagents as described by Ragazzi and Veronese (1973). Prior to this assay, $10-\mu \mathrm{L}$ extracts were put in open aliquots in a flow cabinet to allow vaporization of acetone. Phenolics were subsequently resuspended in $10-\mu \mathrm{L}$ deionized water and assayed. Absorbance was measured at $740 \mathrm{~nm}$ (Nanodrop, ND1000). Tannic acid was used for calibration and results were expressed as tannic acid equivalents $\left(\mathrm{gTAE} \mathrm{gDW}^{-1}\right)$. Treatments were compared by performing a one-way ANOVA with a Tukey-Kramer post hoc test for multiple comparisons of means (Matlab v.7.0).

\section{Results}

Sponge recruitment on mimicry gels containing tannic acid is presented in Fig. 2. An average of seven recruits was recovered from gels with high tannic acid contents $(1.8 \mathrm{nM})$, which was significantly $(P<0.05)$ higher compared to an average of three recovered recruit in mimicry substrates that did 


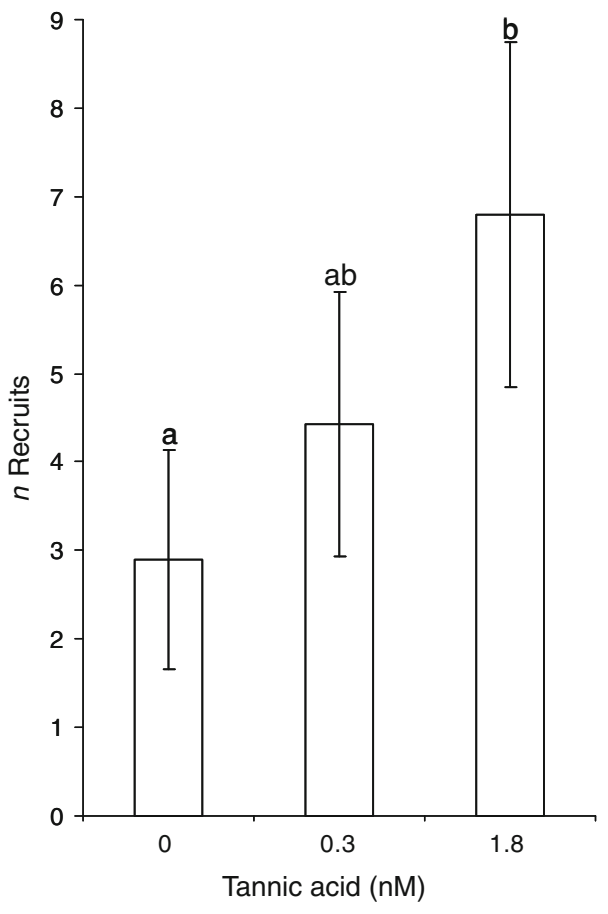

Fig. 2 Average number of sponge recruits on mimicry gels with different tannin concentrations. Provided are means $( \pm$ s.e.). Corresponding letters indicate statistical similarity $(\alpha<0.05 ; n=10$ per treatment $)$

not contain tannic acid. Figure 2 suggests that there is enhanced recruitment in the lower ranges of tannic acid content $(0.3 \mathrm{nM})$; however, there was no statistical difference between the low concentration treatment and that of the zero and high concentration $(1.8 \mathrm{nM})$ treatments. Next to sponge recruits, the mimicry gels also contained some Bryozoa, and each treatment contained a patchy, yet unspecified microbial biofilm. All recruits were $2-3 \mathrm{~mm}$ in size. Over $90 \%$ of the recruits recovered from the mimicry gels were identified as Tedania (Tedania) ignis (Duchassaing and Michelotti) and the remaining species included Desmapsamma anchorata (Carter), Dysidea janiae (Duchassaing \& Michelotti), and Ircinia felix (Duchassaing \& Michelotti).

Total phenolic and tannin concentrations in mangrove roots of the different treatments are presented in Fig. 3a,b, respectively. Following an 8-week incubation period, roots covered with sponges contained approximately $20 \%$ more phenolic compounds and $22 \%$ more tannins than roots that were not covered by
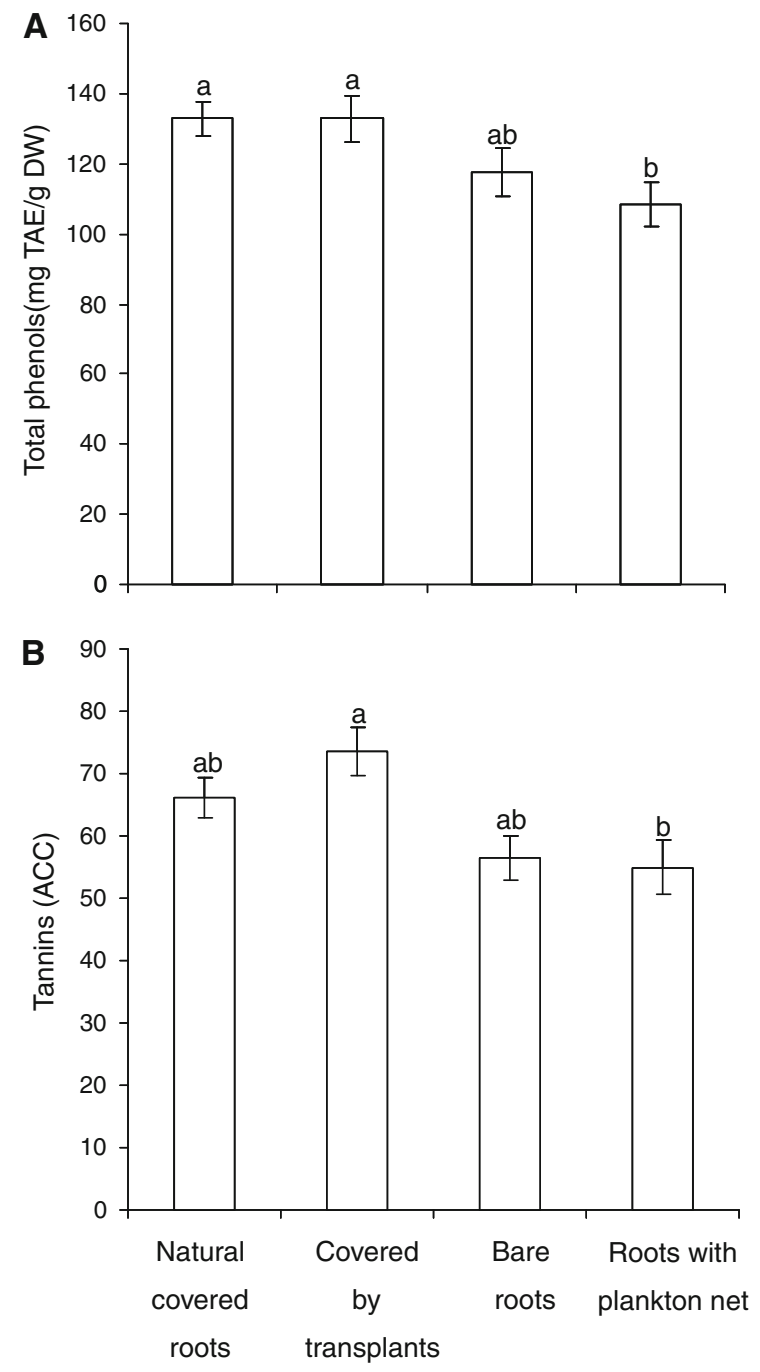

Fig. 3 Concentrations of (a) total phenolic compounds (expressed as tannic acid equivalents, $T A E$ ) and (b) proteinprecipitating tannins (expressed as albumin complexing capacity, $A C C$ ) of mangrove roots after 8 weeks of incubation with four different treatments in Spaanse Water, Curaçao. Treatments include natural covered roots, natural unfouled roots, roots covered with transplants, and roots wrapped in plankton net. Bars indicate means $( \pm$ s.e.), and corresponding letters indicate statistical similarity $(\alpha<0.05 ; n=15$ per treatment)

sponges. Roots covered with transplants contained significantly higher $(P<0.05)$ concentrations of total phenols, and tannins compared to roots covered with plankton net. Furthermore, roots that were naturally covered with sponges expressed a significant $(P<0.05)$ increase in total phenol content compared to roots covered with plankton net. 


\section{Discussion}

The present study demonstrates that recruitment of the sponge Tedania ignis is enhanced when substrates contain higher tannin concentrations. Sponges have short-living lecithotrophic larval stages, and hydrology and stochasticity are considered the principal factors explaining large-scale spatial patterns, while active habitat selection becomes progressively more important at small $(<1 \mathrm{~m})$ spatial scales (Pawlik 1992; Mariani et al. 2006). Since roots of Rhizophora mangle generally provide the only stable substrate in mangrove ecosystems, substrate localization is a critical process for the successful reproduction of mangrove-associated sponges. In order to actively select an appropriate substrate, sponge larva should have the ability to detect and discriminate substratespecific cues. Enhanced recruitment associated with increased tannin concentrations may be the result of a behavioral response of sponge larvae to tannins. However, although larvae of several sponge species are known to actively examine and select an appropriate substrate and chemical stimuli are often considered a cue in selective settlement (Maldonado 2006; Whalan et al. 2008), no unequivocal evidence exists that clearly demonstrates chemotaxis and chemical regulation of settlement in sponge larvae. Alternatively, tannins may have altered the structure of the fouling microbial consortium, and larvae of T. ignis may have subsequently responded to differences in chemical, textural, or structural aspects of the microbial biofilm. In addition, differences in tannic acid contents between treatments may have caused differences in post-settlement dynamics. It is possible that higher tannic acid concentrations may have reduced mortality of sponge recruits due to increased nutrient availability or reduced predation. Irrespective of the mechanism, a direct or indirect influence of tannins on sponge larvae may suggest that secondary metabolites of plants and algae play a pivotal role in substrate selection or post-settlement dynamics and henceforth polyphenolic compounds may be involved in structuring epibiont communities. Future research efforts should elucidate whether larvae of $T$. ignis respond directly to dissolved tannins or polyphenolic compounds or indirectly to possible differences in the fouling microbial assemblages. It is also necessary to evaluate the early stages of sponge community assembly and post-settlement dynamics in relation to tannins and polyphenols in order to gain insight in the ecological relevancy of tannins and polyphenols in sponge community patterns.

Sponge colonization promoted tannin and phenol production in $R$. mangle roots. We can not exclude the possibility that elevations in tannin concentration are physiological responses to stress (e.g., injury). However, we speculate that the elevated concentrations of tannins and polyphenolic compounds upon coverage, combined with differential recruitment of T. ignis in response to differences in tannin concentrations, may result in a positive feedback in recruitment, i.e., settlement induces elevation in secondary metabolites, which in turn enhances the number of recruits. This type of mechanism may help explain among root heterogeneity and would complement a facultative mutualism between $R$. mangle and common root fouling sponges as proposed by Ellison et al. (1996). These authors presented evidence that $R$. mangle roots produce adventitious rootlets generally involved in nutrient uptake that ramify tissue of several sponge species, including T. ignis. They also found that roots of $R$. mangle obtain nitrogen from sponges and that sponges obtain carbon from $R$. mangle roots, while both sponge and tree exhibit enhanced growth rates upon association. In addition, enhanced eutrophic state and experimental fertilization have been shown to result in elevations of R. mangle phenolics (Feller 1995; Feller et al. 2003a, b; Hunting et al. 2008). Elevations of phenolic compounds in this study may therefore indicate that sponge coverage enhances nutrient availability to $R$. mangle roots.

This study aimed to evaluate the role of tannins within the association of sponges and prop roots of the red mangrove $R$. mangle. The results presented here indicate that tannins are directly or indirectly involved in the recruitment of the sponge T. ignis and suggest that the ecological role of tannins within the mangrove sponge association is more complex than previously anticipated.

Acknowledgments Fieldwork was conducted at the Carmabi foundation, Curaçao N. A. and was funded by the SchureBeijerinck-Popping fund of the Dutch Royal Academy of Science (KNAW). The authors express their gratitude to the anonymous referees, Michiel Kraak, Peata Ratsanik, and Merrin Whatley for their constructive comments on earlier drafts of this article. 
Open Access This article is distributed under the terms of the Creative Commons Attribution Noncommercial License which permits any noncommercial use, distribution, and reproduction in any medium, provided the original author(s) and source are credited.

\section{References}

Baylor ER, Sutcliffe WH (1963) Dissolved organic matter in seawater as a source of particulate food. Limnol Oceanogr 8:369-371

Bingham BL (1992) Life histories in an epifaunal communitycoupling of adult and larval processes. Ecology 73(6): 2244-2259

Browne KA, Zimmer RK (2001) Controlled field release of a waterborne chemical signal stimulates planktonic larvae to settle. Biol Bull 200:87-91

Bryant JP, Clausen TP, Reichardt PB, McCarthy MC, Werner RA (1987) Effect of nitrogen fertilization upon secondary chemistry and nutritional value of quaking aspen (Populus tremuloides Michx.) leaves for the large aspen tortrix (Choristoneura conflictana (Walker)). Oecologia 73(4): 513-517

Camilleri JC, Ribi G (1986) Leaching of dissolved organic carbon (DOC) from dead leaves, formation of flakes from DOC, and feeding on flakes by crustaceans in mangroves. Mar Biol 91(3):337-344

Ellison AM, Farnsworth EJ (1996) Spatial and temporal variability in growth of Rhizophora mangle saplings on coral cays: links with variation in insulation, herbivory, and local sedimentation rate. J Ecol 84-5:717-731

Ellison AM, Farnsworth EJ, Twilley RR (1996) Facultative mutualism between red mangroves and root-fouling sponges in Belizean mangal. Ecology 77(8):2431-2444

Engel S, Pawlik JR (2005) Interactions among Florida sponges. II. Mangrove habitats. Mar Ecol Prog Ser 303:145-152

Feller IC (1995) Effects of nutrient enrichment on growth and herbivory of dwarf red mangrove (Rhizophora mangle). Ecol Monogr 65(4):477-505

Feller IC, Whigham DF, McKee KL, Lovelock CE (2003a) Nitrogen limitation of growth and nutrient dynamics in a disturbed mangrove forest, Indian River Lagoon, Florida. Oecologia 134(3):405-414

Feller IC, McKee KL, Whigham DF, O'Niell JP (2003b) Nitrogen versus phosphorus limitation across an ecotonal gradient in a mangrove forest. Biogeochemistry 62(2): 145-175

Hagerman AE (1987) Radial diffusion assay for determining tannin in plant extracts. J Chem Ecol 13(3):437-449
Haukioja E, Ossipov V, Koricheva J, Honkanen T, Larsson S, Lempa K (1998) Biosynthetic origin of carbon-based secondary compounds: cause of variable responses of woody plants to fertilization? Chemoecology 8:133-139

Henrikson AA, Pawlik JR (1995) A new antifouling assay method: Results from field experiments using extracts of four marine organisms. J Exp Mar Biol Ecol 194(2): 157-165

Hooper JNA, Van Soest RWM (2002) Systema porifera. Kluwer Acedamic/Plenum publishers, New York

Hunting ER, Van Soest RWM, Van der Geest HG, Vos A, Debrot AO (2008) Diversity and spatial heterogeneity of mangrove associated sponges of Curaçao and Aruba. Contrib Zool 77(4):205-215

Kuznetsova AM, Orlova OV, Savinov AB (1984) Aggregates of organic matter in fresh waters and their role in the nutrition of small filter feeder crustaceans. Gidrobiol $\mathrm{Zh}$ 20:3-8

Lin Y-M, Liu JW, Xiang P, Lin P, Ye GF, Strernberg DSL (2006) Tannin dynamics of propagules and leaves of Kandelia candel and Bruguiera gymnorrhiza in the Jiulong River Estuary, Fujian, China. Biogeochemistry 78:343-359

Maie N, Jaffe R (2006) Quantitative and qualitative aspects of dissolved organic carbon leached from senescent plants in an oligotrophic wetland. Biogeochemistry 78(3):285-314

Maldonado M (2006) The ecology of the sponge larva. Can J Zool 84(2):175-194

Mariani S, Uriz MJ, Turon X, Alcoverro T (2006) Dispersal strategies in sponge larvae: integrating the life history of larvae and the hydrologic component. Oecologia 149(1): 174-184

Northup RR, Dahlgren RA, McColl JG (1998) Polyphenols as regulators of plant-litter-soil interactions in Northern California's pygmy forest: a positive feedback? Biogeochemistry 42:189-220

Pawlik J (1992) Chemical ecology of the settlement of benthic marine invertebrates. Oceanogr Mar Biol Annu Rev 30:273-335

Ragazzi E, Veronese G (1973) Quantitative analysis of phenolics compounds after thin-layer chromatographic separation. J Chromatogr 77:369-375

Schmitt TM, Lindquist N, Hay ME (1998) Seaweed secondary metabolites as antifoulants: effects of Dictyota spp. diterpenes on survivorship, settlement, and development of marine invertebrate larvae. Chemoecology 8:125-131

Sutherland JP (1980) Dynamics of the epibenthic community on roots of the mangrove Rhizophora mangle, at Bahía de Buche, Venezuela. Mar Biol 85:75-84

Whalan S, Ettinger-Epstein P, Battershill C, de Nys R (2008) Larval vertical migration and hierarchical selectivity of settlement in a brooding marine sponge. Mar Ecol Prog Ser 368:145-154 